\title{
Movement stability of vehicles with a rigid and free wheels mounting on wheelset axles
}

\author{
Volodymyr Hovorukha ${ }^{1, *}$ \\ ${ }^{1}$ Institute of Geotechnical Mechanics named by N. Poljakov of National Academy of Sciences of \\ Ukraine, 49005, Dnipro, Simferopolska Str., 2a, Ukraine
}

\begin{abstract}
The article considers the actual task of improving mobile units of underground rail transport, taking into account the peculiarities of work in straight and curvilinear sections of the path of especially small curvature radius of $8-50 \mathrm{~m}$, with reference to the rail track width of $600 ; 750$ and $900 \mathrm{~mm}$. The purpose of the work is to improve operational performance of rail transport of mining enterprises and improve safety of railway movements. Methods for the study of interaction processes of mobile vehicles and the rail track are presented. The study results of loading, oscillations and movement stability of vehicles with the free and rigid mounting of wheels on the axles of wheelsets are given. The resonance phenomenon due to the proximity of frequencies of forced and natural oscillations of mobile units of underground rail transport has been established. The obtained results can be applied to the development of normative documents regulating tolerances for the maintenance of rail track in the plan, profile and for the broadening of the track, taking into account the vertical, horizontal and longitudinal irregularities of the rail threads. The study results can be used to improve the design of mobile vehicles and rail track.
\end{abstract}

\section{Introduction}

A wide variety of tasks solved in rail transport mechanics was based on the principle of rigid mounting of wheels on axles of wheelsets [1-9] and others. In contrast to railway rail transport in industrial rail transport of underground mining enterprises, four-axle, two-axle wagons and sectional trains are used, whose wheels have a free rotation on the axles of wheelsets. Such constructive solutions are caused by the presence of curvilinear sections of the railway track with radius of $8-50 \mathrm{~m}$. In this case, the width of the rail track of narrow gauge vehicle is $600 ; 750$ and $900 \mathrm{~mm}$.

Studies and methods for calculating the mechanics of the movement processes of mobile units of narrow gauge mining transport were based on the principle of rigid mounting of wheels on axles of wheelsets [7-9] and others.

Such assumptions about a rigid mounting of the wheels do not correspond to the design of narrow gauge vehicles, where the free rotations of the wheels on the axles of the wheelsets are used. At the same time, the results of theoretical studies did not correspond to

*Corresponding author: igtm.rail.trans@gmail.com 
reality and led to incorrect technical solutions when creating rail vehicles, developing regulatory documents and ensuring the safety of railway operation. Therefore, the research relevance is determined by the operational requirement and the correctness of methods of study of indicators of the vehicle performance.

Below are the features of mathematical modeling of the movement of four-axle mine carriages, as well as the results that take into account the specificity of wheels mounting on the axles of wheelsets in accordance with the design of mobile units of the studied carriage rolling stock. The spatial movement of the mine rolling stock along the track of arbitrary curvature with irregularities in plan and deviations along the track gauge width is considered. In the dynamics of mine rolling stock, these issues have not previously been considered and are relevant.

The purpose of the work is to determine the indicators of vehicle stability based on studies of the interaction process of mobile units with a free and rigid mounting of wheels on the axles of wheelsets and the rail track that has straight and curved sections of the track with vertical and horizontal irregularities. These features determine the load, fluctuations, stability and safety of vehicles movement.

\section{Methods}

For the study of vehicle mechanics, the most important are dynamic indicators of loading, oscillations and motion stability factors. Accepted most characteristic mobile units represented by four-axle mine wagons of high payload (up to 50.0 tons of rock mass) with the track gauge of $750 \mathrm{~mm}$ and radii of curves of $8-50 \mathrm{~m}$ in case of interaction with elements of the rail track, having significant deviations along the uneven surfaces in horizontal, transverse and vertical planes, and irregularities in the plan and profile of the movement route.

The vehicle is represented by a four-axle wagon with a free and rigid mounting of wheels on the axles of wheelsets, where the mechanical system consists of solids (body, carriage frames, wheelsets or axles of wheelsets and wheels rigidly or freely mounted on the axle of wheelsets) interconnected by elastic-dissipative, rigid or swiveling links.

In Figure 1, $a, b, c$ is shown the calculation scheme of the studied transport system with the free rotation of the wheels relative to the axles of the wheelsets. The calculation scheme of the transport system with a rigid wheel mounting on the axles of the wheelsets has an analogy with the calculation scheme shown in Figure 1, $a, b, c$, except the rigid combination into one whole of a pair of wheels and axles of wheelsets.

The rail track under each wheel of the vehicle is represented by a chain of solid bodies in the vertical and transverse directions, modeling its main constituent elements (rails, rail base, cross-sleepers, under-sleepers base) interconnected by elasticdissipative links and elements. In this case, the viscous resistance proportional to the relative velocity of movement of solids and the dry friction between bodies is taken into account (Fig. 1, $a, b, c)$.

For the construction of mathematical models corresponding to the process of vehicle movement along the track of an arbitrary outline in the plan, one fixed coordinate system $\tilde{O} \xi \eta \zeta$ was used, and for each solid body of the studied mechanical system, two movable systems were used: natural $O x y z$ and permanently connected with a solid body $C x^{\prime} y^{\prime} z^{\prime}$ (Fig. 2, $a, b$ ) in accordance with works $[3,5,11]$.

The position of such a coordinate system, as applied to Figure 2, is described by the arc coordinate along the axis of the path $S$, the angle $\chi$ between the tangent to the axis of the path and the fixed axis Õ $\xi$, the angle of inclination $\vartheta_{h}$ of the rail track surface in the transverse plane due to the elevation of the outer rail $h$. Spherical motion is determined by 
three angles: $\widetilde{\psi}=\psi+\chi ; \varphi ; \widetilde{\vartheta}=\vartheta+\vartheta_{h}$, defining turns of the main central axes $C x^{\prime}, C y^{\prime}, C z^{\prime}$ relative to a fixed coordinate system.

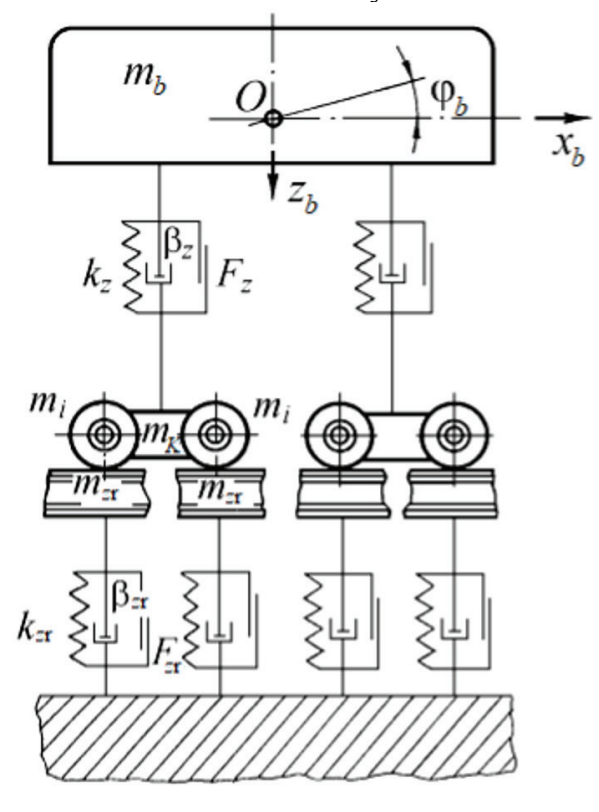

$a$

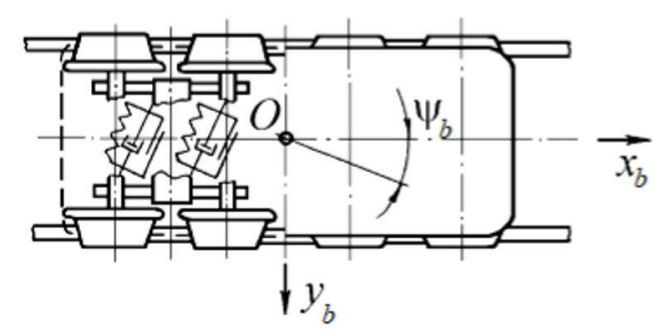

$c$

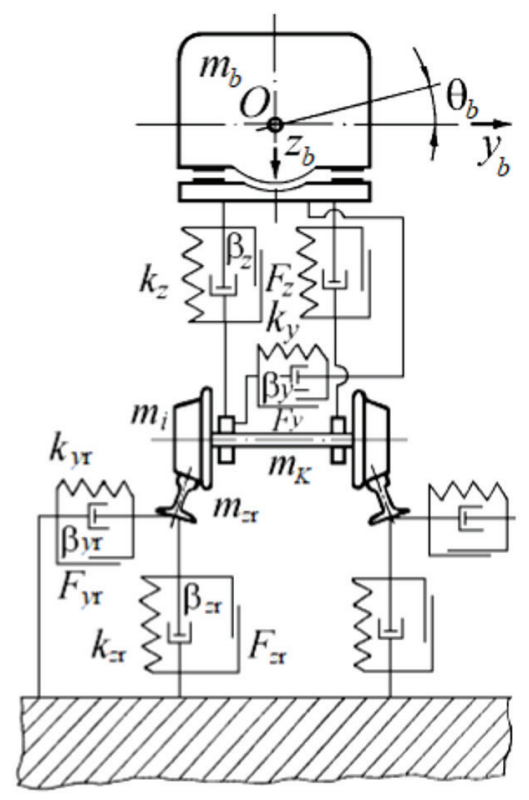

$b$

Fig. 1. The calculation scheme of a four-axle wagon with wheels rigidly mounted on the axle of the wheelsets, and a single mass track structure: $a$ - side view; $b$ - view from above; $c$ - end view.

Linear movements of the carriage body are indicated through $x_{b}, y_{b}, z_{b}$, and the angular through $\psi_{b}, \varphi_{b}, \vartheta_{b}$. Translational movements $x, y, z$ describe, respectively, shuttle motion, lateral motion and vertical motion, and the angles of rotation $\psi, \varphi, \vartheta$ describe wabbing, galloping motion and rolling motion.

As generalized coordinates $q_{v}$, linear in transverse and vertical directions $y, z$ and angular displacements $\vartheta, \varphi, \psi$ of solids corresponding to the wagon (body and its chassis) and linear displacements $x, y$ and $z$ of solids corresponding to the rail track were taken.

Mathematical models of the movement of the cars under study were obtained using the Lagrange equations of the second kind. In the general form of the equation of motion of wagons on the rail track is presented in the form:

$$
D_{v}+P_{v}+S_{v}=Q_{v}, \quad v=(1,2, \ldots, N)
$$


Where $N$ is the number of degrees of freedom; $D_{v}, P_{v}, S_{v}$ are the differential operators corresponding to the Lagrange equations of the second kind:

$$
D_{v}=\frac{d}{d t}\left(\frac{\partial K}{\partial \dot{q}_{v}}\right)-\frac{\partial K}{\partial q_{v}}, P_{v}=\frac{\partial P}{\partial q_{v}}, S_{v}=\frac{\partial S}{\partial \dot{q}_{v}}
$$

$Q_{v}$ is generalized forces corresponding to generalized coordinates $q_{v} ; K, P, S$ are kinetic, potential energy and scattering function; $\dot{q}_{v}$ is the speed of generalized coordinates (first time derivative).

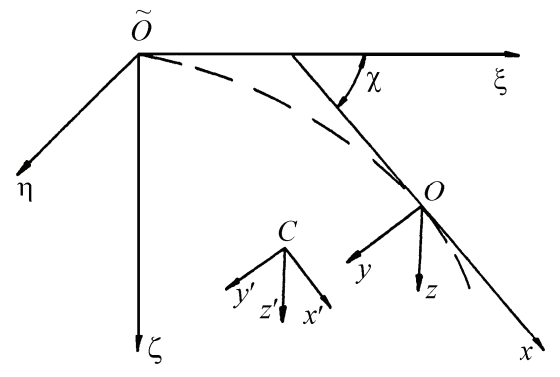

$a$

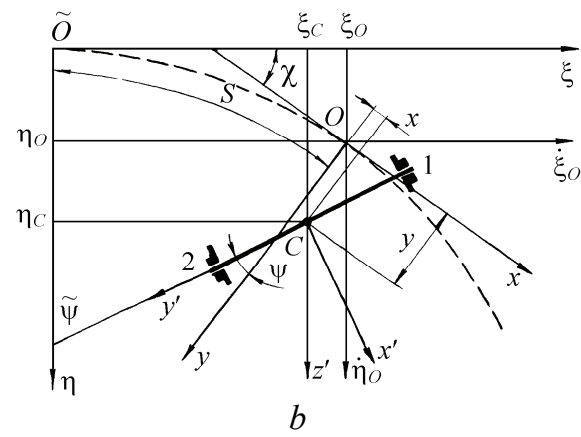

Fig. 2. Carriage motion coordinate systems: $a$ - common coordinate system; $b-$ wheelset motion scheme.

Under the accepted initial assumptions, the expressions $D_{v}, P_{v}, S_{v}$ can be represented as:

$$
D_{v}=f\left(m, I, q_{v}, \ddot{q}_{v}\right), \quad P_{v}=f\left(k, q_{v}\right)+P_{h}\left(q_{v}\right) S_{v}=f_{2}\left(\beta, \dot{q}_{v}\right)+f_{3}\left(F, \dot{q}_{v}\right),
$$

where $m$ and $I$ are inertial characteristics (masses and moments of inertia) of system solids; $\ddot{q}_{v}$ is the acceleration of the generalized coordinates (second time derivative); $k$ and $\beta$ are coefficients of the stiffness of elastic and the viscosity of dissipative elements, respectively, of the wagon, rails, cross-sleepers and base; $F$ is forces of dry friction in the bonds between solids, respectively, of the wagon, rails, cross-sleepers and base; $P_{h}\left(q_{v}\right)$ is component of potential energy, caused by the change in height of the centers of gravity of solids during movement $q_{v}$.

The generalized forces $Q_{v}$ were defined as functions of the interaction forces between the wheels and the rails $P_{n j}, F_{y n j}, X_{n j}$ in the vertical, transverse and longitudinal directions (here $n$ is the number of the wheelset, $j=1,2$ is the number of the wheel of the $n$-th wheelset).

Note the distinctive features of the determination of forces $P_{n j}, F_{y n j}, X_{n j}$ for cases of free and rigid mounting of the wheels on axles of wheelsets. 
The forces $P_{n j}$ acting on the wheels in the vertical direction were, in general, equally calculated and represented the sum of static and dynamic forces determined through dynamic deflections and their time derivatives and through stiffness and viscosity coefficients (or dry friction forces) of spring suspension elements.

The interaction forces of wheels with rails in the transverse direction $F_{y n j}$ were determined as the sum of the pseudo-slippage forces in the transverse direction $y_{n j}$ and the lateral pressure forces of the wheel flanges on the railheads $W_{n j}=-P_{n j} \frac{d r_{n j}}{d y_{n j}}$, where $r_{n j}$ is the increment of the wheels radii in case of they transversely move relative to the rails $y_{n j}$.

The tangential forces of the interaction of wheels with rails (pseudo-slip forces) $F_{n j}$, based on the creep hypothesis, taking into account their non-linear dependence on dimensionless slip characteristics, were found from the expression:

$$
F_{n j}=-f_{n j} \varepsilon_{n j}\left[\left(\frac{f_{n j} \xi_{n j}}{k_{f} P_{n j}}\right)^{2}+1\right]^{-1 / 2}
$$

where $f_{n j}$ is the pseudo-slippage coefficients, determined in accordance with the works $[3,5] ; k_{f}$ is the coefficient of friction between wheels and rails.

The components of the pseudo-slippage forces $X_{n j}, Y_{n j}$ in the longitudinal and transverse directions were determined from the expressions:

$$
X_{n j}=F_{n j} \frac{\varepsilon_{x n j}}{\varepsilon_{n j}}, \quad Y_{n j}=F_{n j} \frac{\varepsilon_{y n j}}{\varepsilon_{n j}},
$$

where $\varepsilon_{n j}, \varepsilon_{x n j}, \varepsilon_{y n j}$ are dimensionless wheel slip characteristics and their components in the longitudinal and transverse directions $\varepsilon_{n j}=\left(\varepsilon_{x n j}^{2}+\varepsilon_{y n j}^{2}\right)^{1 / 2}$.

The components of the dimensionless slip characteristics $\varepsilon_{y n j}$ for rigid and free wheel mounting were determined from the expression:

$$
\varepsilon_{y n j}=\frac{1}{\mathrm{v}} \dot{y}_{n j}^{*}-\psi_{n j}
$$

and the component of the dimensionless characteristic $\varepsilon_{x n j}$ is determined from the expressions:

$$
\varepsilon_{x n j}=(-1)^{j+1}\left[\frac{d_{1}}{\mathrm{v}}\left(\dot{\psi}_{n j}+\dot{\chi}_{n j}\right)+(-1)^{j} \frac{\Delta r_{n j}}{r}\right],
$$

for the rigid mounting of wheels and

$$
\varepsilon_{x n j}=(-1)^{j+1}\left[\frac{d_{1}}{v}\left(\dot{\psi}_{n j}+\dot{\chi}_{n j}\right)+(-1)^{j} \frac{\Delta r_{n j}}{r}+(-1)^{j} \frac{r \dot{\varphi}_{n j}}{v}\right],
$$

for the free mounting of wheels.

Here $v$ is the speed of the uniform movement of the vehicle, $\dot{y}_{n j}^{*}$ is the relative speed of movement of the points of contact of the wheels and railheads, $2 d_{1}$ is the distance between the middle wheels rolling circles of the wheelset, $r$ is the radius of the middle wheels rolling 
circle, $\dot{\chi}_{n j}$ is the angular velocity determined by the curvature of track, under the $j$-th wheel of the $n$-th wheelset.

The horizontal irregularities were defined as a sine wave or a cosine wave, and vertical irregularities (including butt joints) were defined as a cosine curve of a limited length within one period or complex irregularities.

\section{Results and discussion}

In order to estimate the dynamic loading, oscillations and stability of four-axle wagons on the rail track, the main initial data are given in Table 1.

The irregularities of the path in the plan of were set in the form of a sine wave or a cosine wave, and the butt joint vertical irregularities were set in the form of a cosine wave of limited length within one of its periods.

The evaluation of the calculation schemes of the studied transport systems was carried out according to indicators characterizing the load of the running gears, spring sets of tip wagons and rail tracks in the vertical and transverse directions, and according to the indicators of vehicles movement safety, in particular, characterizing the stability of the assembled rails and sleepers shear, wheels unloading, wheels rolling in on the rails. Therefore, as criteria for evaluating the dynamic indicators of the studied types of mine rolling stock, the maximum values of the forces acting on the wheels, spring sets and rail threads in the vertical and transverse directions $p_{n j}, Q_{y n j}, F_{z n j}, F_{y n j}$ and $Q_{z n j r}, Q_{y n j r}$ respectively, the transverse forces $Q_{y n}$ acting on the wheelsets, the stability factors from wheels unloading $k_{u n l}$, assembled rails and sleepers shear $k_{s h}$ and from wheels rolling in on the rails $k_{\text {roll }}$ are selected.

Figure 3 shows examples of vertical and transverse movements of the tip wagon body with rigidly fixed wheels on the axles (Fig. 3, $a, b$ ) and free wheel rotation on the axles (Fig. 3, c, d) when moving along a curved path without irregularities. In this case, in Figure 3, $a, b$ vertical motions (jumping) are given, and in Figure 3, $c, d$ transverse motions (lateral motion) are given.

Comparative analysis of chattering, load and stability of movement of wagons with rigid and independent wheels mounting on axles of wheelsets shows a significant difference in the main dynamic indicators in the transverse direction, including lateral loads $Q_{y n j}, Q_{y i n j}, Q_{y i n j r}, Q_{y i n j s}$, and oscillations amplitudes in the elements of the movable unit of the rail track structure, as well as a slight difference in indicators of load $P_{z i n}, Q_{z i n j}, Q_{y i n j s}$ and oscillation amplitudes in the vertical plane.

At the same time, the difference of the largest values of horizontal forces of interaction between wheels and wheelsets with the rail track structure elements in a steady motion mode of the tip wagon with the rigid and free wheels mounting on axles of wheelsets on straight sections of the rail track is approximately $40 \%$ for forces acting on wheelsets $Q_{y i n}, 30 \%$ for the forces acting on the wheels $Q_{y i n j}, 15 \%$ for the forces transmitted to the rails $Q_{y i n j r}$ and for the forces transmitted to the cross-sleepers $Q_{y i n j s}$ and its base $Q_{y i n j}$. On curvilinear sections of the path, this difference accordingly reaches $20 \%$ for forces $Q_{y i n}, 25 \%$ for forces $Q_{y i n j}, 30 \%$ for forces $Q_{y i n j p}, Q_{y i n j s}, Q_{y i n j b}$. As can be seen, the greatest discrepancy in the values of lateral forces occurs on straight sections of the path.

The indicators characterizing the tip wagons movement safety are also significantly different for various calculation schemes that take into account design features due to the free and rigid mounting of the wheels on axles of wheelsets. 
Table 1. Initial data for a four-axle tip wagon of WG-28-900 type with a free mounting of wheels.

\begin{tabular}{|c|c|c|c|}
\hline Parameter & Symbol & Dimension & Value \\
\hline Tip wagon body weight (with load) & $m_{b}$ & $\mathrm{t}$ & 33.385 \\
\hline Weight of unsprung carriage bogie part & $m_{c}$ & $\mathrm{t}$ & 1.008 \\
\hline Wheelset weight & $m_{i}$ & $\mathrm{t}$ & 0.186 \\
\hline Wheel weight & $m_{\text {in }}$ & $\mathrm{t}$ & 0.083 \\
\hline $\begin{array}{l}\text { Reduced mass of rails in: } \\
\text { transverse direction } \\
\text { vertical direction }\end{array}$ & $\begin{array}{l}m_{y \mathrm{r}} \\
m_{\mathrm{zr}}\end{array}$ & $\begin{array}{l}t \\
t\end{array}$ & $\begin{array}{l}0.05 \\
0.13\end{array}$ \\
\hline Static load on wheel & $P_{\text {stat }}$ & $\mathrm{kN}$ & 4.42 \\
\hline Tip wagon base & $2 L$ & $\mathrm{~m}$ & 4.0 \\
\hline Base of the two-axis carriage bogie & $2 a$ & $\mathrm{~m}$ & 1.1 \\
\hline $\begin{array}{l}\text { Distance between the axes of the elastic } \\
\text { elements supporting the bolster on the bogie } \\
\text { frame in the transverse direction }\end{array}$ & $2 b$ & $\mathrm{~m}$ & 0.55 \\
\hline $\begin{array}{l}\text { Distance between the axes of the edge elastic } \\
\text { elements of the supporting bolster on the bogie } \\
\text { frame in the longitudinal direction }\end{array}$ & $2 a_{1}$ & $\mathrm{~m}$ & 0.44 \\
\hline Average radius of the rolling circle of wheels & $r$ & $\mathrm{~m}$ & 0.2 \\
\hline $\begin{array}{l}\text { Distance from the gravity center of the body to } \\
\text { the plane of its bearing on the elastic elements }\end{array}$ & $H$ & $\mathrm{~m}$ & 0.65 \\
\hline $\begin{array}{l}\text { Distance between the average rolling circles of } \\
\text { wheels }\end{array}$ & $2 d_{1}$ & $\mathrm{~m}$ & 0.947 \\
\hline $\begin{array}{l}\text { Gap clearance between wheel flange and } \\
\text { railhead }\end{array}$ & $\delta_{0}$ & $\mathrm{~mm}$ & 10 \\
\hline $\begin{array}{l}\text { Stiffness of the elastic elements of the } \\
\text { suspension of the body on the frame of the } \\
\text { carriage bogie in: } \\
\text { transverse direction } \\
\text { vertical direction }\end{array}$ & $\begin{array}{l}2 k_{y} \\
4 k_{z}\end{array}$ & $\begin{array}{l}\mathrm{kN} / \mathrm{m} \\
\mathrm{kN} / \mathrm{m}\end{array}$ & $\begin{array}{c}6420 \\
12840\end{array}$ \\
\hline $\begin{array}{l}\text { Viscous drag coefficients for wagon dampers in: } \\
\text { transverse direction } \\
\text { vertical direction }\end{array}$ & $\begin{array}{l}2 \beta_{y} \\
4 \beta_{z}\end{array}$ & $\begin{array}{l}\mathrm{kN} \cdot \mathrm{s} / \mathrm{m} \\
\mathrm{kN} \cdot \mathrm{s} / \mathrm{m}\end{array}$ & $\begin{array}{c}60 \\
120\end{array}$ \\
\hline $\begin{array}{l}\text { Dry friction in the wagon dampers in: } \\
\text { transverse direction } \\
\text { vertical direction }\end{array}$ & $\begin{array}{l}2 F_{y} \\
4 F_{z}\end{array}$ & $\begin{array}{l}\mathrm{kN} \\
\mathrm{kN}\end{array}$ & $\begin{array}{l}0.2 \\
0.4\end{array}$ \\
\hline $\begin{array}{l}\text { Viscous drag coefficients for rail path dampers: } \\
\text { transverse direction } \\
\text { vertical direction }\end{array}$ & $\begin{array}{l}\beta_{y \mathrm{r}} \\
\beta_{z \mathrm{r}}\end{array}$ & $\begin{array}{l}\mathrm{kN} \cdot \mathrm{s} / \mathrm{m} \\
\mathrm{kN} \cdot \mathrm{s} / \mathrm{m}\end{array}$ & $\begin{array}{l}20 \\
10\end{array}$ \\
\hline $\begin{array}{l}\text { Dry friction in the rail path dampers in: } \\
\text { transverse direction } \\
\text { vertical direction }\end{array}$ & $\begin{array}{l}F_{y \mathrm{r}} \\
F_{z \mathrm{r}}\end{array}$ & $\begin{array}{l}\mathrm{kN} \\
\mathrm{kN}\end{array}$ & $\begin{array}{l}6 \\
4\end{array}$ \\
\hline $\begin{array}{l}\text { Weight of the wheelset with the rigid mounting } \\
\text { of wheels }\end{array}$ & $m_{i}$ & $\mathrm{t}$ & 0.327 \\
\hline
\end{tabular}

The decisive condition for the tip wagons movement safety, as shown by research results, is movement along curved sections of the rail track. For the considered cases in the steady-state motion mode, the minimum value of the rolling in stability coefficient is 2.8 for the calculation scheme of the tip wagon with free rotation of wheels and 2.0 for the calculation scheme of the tip wagon with rigid mounting of wheels, and the maximum values of the stability coefficient from shear for calculation scheme of with free and rigid mounting of the wheels on their axes, respectively, are 0.18 and 0.22 , which is significantly less than the maximum permissible values $\left(k_{\text {roll } \min }=1.5 ; k_{\text {sh } \min }=0.4\right)$. 

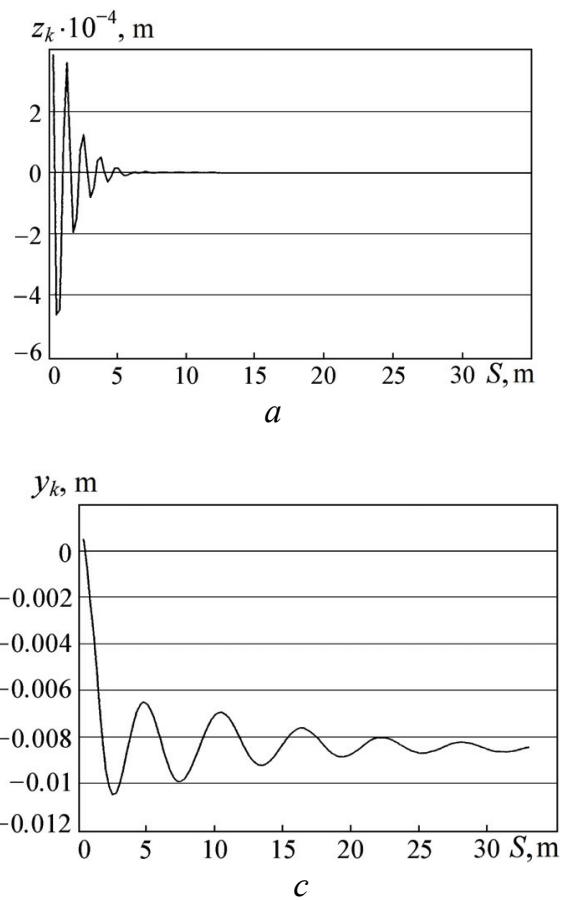
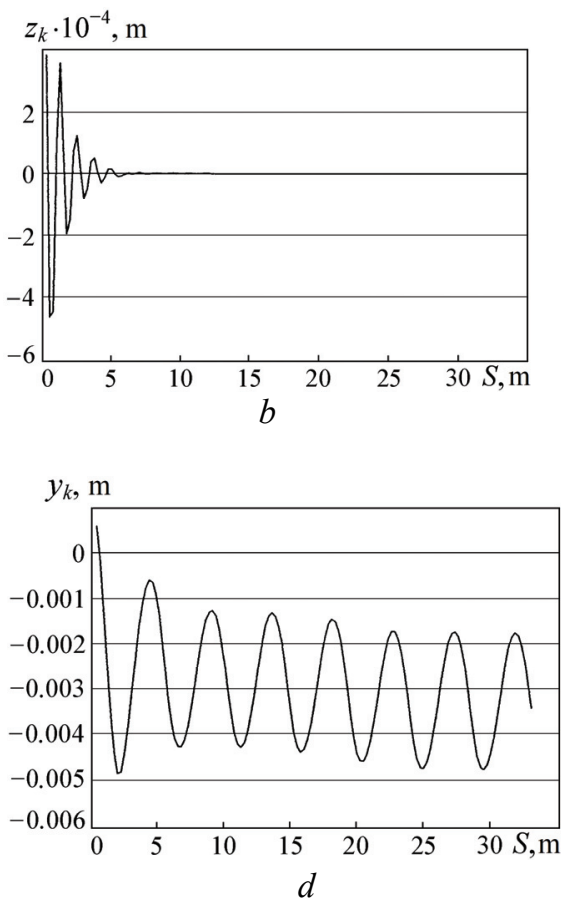

Fig. 3. Vertical and transverse movement of the tip wagon body.

As the analysis of the obtained data shows, the tip wagons movement safety from the condition of wheel unloading and tilting of the tip wagon is ensured with a large margin. So the value of the wheel unloading coefficient is determined by:

$$
k_{u n l}=\frac{P_{s t a t}-P_{i n j \min }}{P_{s t a t}}
$$

for the considered calculation options it does not exceed 0.32 , and the value of the tilting stability coefficient is:

$$
k_{\text {tilt }}=\frac{M_{\text {satb }}}{M_{\text {tilt }}}
$$

where $M_{\text {stab }}$ and $M_{\text {tilt }}$ are stabilizing and tilting moments, approximately equal to 15 .

The results analysis of studies of oscillations, loading and tip wagons movement safety using the considered methods showed that their character is determined primarily by the condition of the rail track. Therefore, the assessment of dynamic characteristics of the tip wagons and the mine rail track during the movement along deterministic vertical butt joint irregularities described by a cosine wave within one period, as well as horizontal irregularities, in plan of a continuous sinus wave is being carried out.

To identify the most unfavorable modes of the elements of motion, the influence of the parameters of irregularities (length and depth within a period) is estimated. In particular, the length of irregularities will vary in the range of $l_{I}=0.5 \ldots 10.0 \mathrm{~m}$, taking the length of vertical irregularities $l_{I}$ to be $0.5 ; 1.0 ; 2.0 ; 5.0 ; 10.0 \mathrm{~m}$, and horizontal irregularities $l_{I}^{\prime}$ equal to $1.0 ; 2.0 ; 3.0 ; 4.0 ; 4.5 ; 5.0 ; 6.0 ; 8.0 ; 10.0 \mathrm{~m}$.

For each of these values $l_{I}, l_{I}^{\prime}$, the vertical irregularity depth $A_{I}=0.005 ; 0.010 ; 0.015$ 
and $0.025 \mathrm{~m}$, and the horizontal $A_{I}^{\prime}=0.005 ; 0.015 ; 0.030$ and $0.050 \mathrm{~m}$ will be taken.

The maximum values of the vertical and transverse forces $P_{i n j}, Q_{z i n j r}, Q_{y i n j}, Q_{y i n j r}, Q_{y i n}$ acting on the wheels and wheelsets, and $F_{z}$ and $F_{y}$, in the elastic-dissipative elements of the spring suspension, as well as extreme values of indicators characterizing wagons movement safety (coefficients of stability from wheels rolling in $k_{\text {roll }}$, from assembled rails and sleepers shear $k_{s h}$ and from wheels unloading $k_{u n l}$ ) are taken as criteria for evaluating the dynamic characteristics of the studied mechanical system.

The results analysis of studies of the movement of the four-axle tip wagon along the straight section of the rail track and the curved radius $R=30 \mathrm{~m}$ with an elevation of the outer rail above the inner one, equal to $0.07 \mathrm{~m}$, showed that the movement of the tip wagon along straight and curvilinear sections of the rail track without irregularities is stable, moreover self-oscillations for the unsprung parts are not observed, which is one of the necessary conditions for achieving satisfactory performance.

From the results obtained in the study of the self-induced oscillations of the tip wagon, it should be noted that for this system, the approach of lateral motion and rolling motion frequency $v_{l r}$ is most expressed with the body chattering and pitching frequencies $v_{c p}$. These frequencies are dependent on the velocity of movement. In case of the tip wagon motion along the straight section of the rail track with the speed of $5 \mathrm{~m} / \mathrm{s}$, the frequency is $v_{l r}=0.86 \ldots 0.90 \mathrm{~Hz}$ and $v_{c p}=4.00 \ldots 4.15 \mathrm{~Hz}, v_{l r}=1.07 \mathrm{~Hz}$ and $v_{c p}=4.0 \mathrm{~Hz}$, and during the movement along the curve is $R=30 \mathrm{~m}, v_{l r}=1.07 \mathrm{~Hz}$ and $v_{c p}=4.0 \mathrm{~Hz}$.

Similar results were also obtained at speeds of $v=3.0 \mathrm{~m} / \mathrm{s}$ and $v=6.0 \mathrm{~m} / \mathrm{s}$.

Analysis of the study of forced oscillations during the movement of the four-axle tip wagon along straight and curved sections of the path with irregularities showed that when driving along the path with vertical irregularities, the most dangerous modes arise (they are caused by wheels unloading), and when moving along the path with horizontal irregularities, modes arise due to wheels rolling in on rails and assembled rails and sleepers shear.

Figure 4 shows examples of graphs of the dependence of the maximum values of the vertical and horizontal forces acting on the wheels, as well as the wheels unloading coefficients, on the parameters of the horizontal irregularities of the straight rail track without vertical irregularities.

As can be seen from the graphs of Figure 4, the maximum value of the interaction forces of the wheels and wheelsets with elements of the rail track $P_{i n j}, Q_{z i n j r}, Q_{y i n j}, Q_{y i n j r}$, $Q_{y i n}$, the forces $F_{z}, F_{y}$ operating in the elastic-dissipative elements of the spring suspension, and the extreme values of the coefficients $k_{u n l}, k_{\text {sh }}, k_{\text {roll }}$ characterizing wheels unloading and the tip wagons movement safety, were obtained with the length of irregularities within one period $l_{I}^{\prime}=5.5 \mathrm{~m}$. At a speed of $v=5 \mathrm{~m} / \mathrm{s}$, this length corresponds to the frequency of forced oscillations in $0.91 \mathrm{~Hz}$, which practically coincides with the frequency of lateral motion and rolling motion of the body.

Thus, at $l_{I}^{\prime}=5.5 \mathrm{~m}$ there is resonance, as a result of which there is a sharp increase in load indicators, which leads to a decrease in movement safety indicators. It is established that each value of the speed of the wagon corresponds to the value of the irregularities, at which the phenomenon of resonance can occur $\left(l_{I}^{\prime}=v / v\right)$, where $v$ is the frequency of natural oscillations of the lateral motion and rolling motion of the unsprung wagon parts. Thus, at speeds $v=v l_{I}^{\prime}$ for the wagon, resonant modes may appear, due to periodic transverse irregularities of the rail track. 


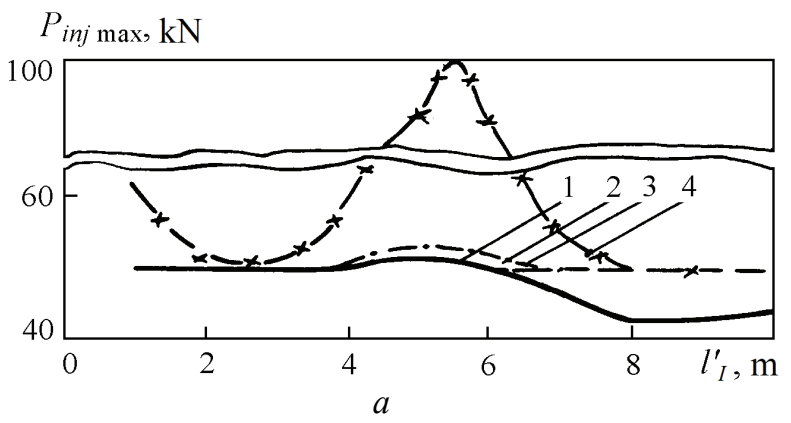

$Q_{\text {zinjr max }}, \mathrm{kN}$
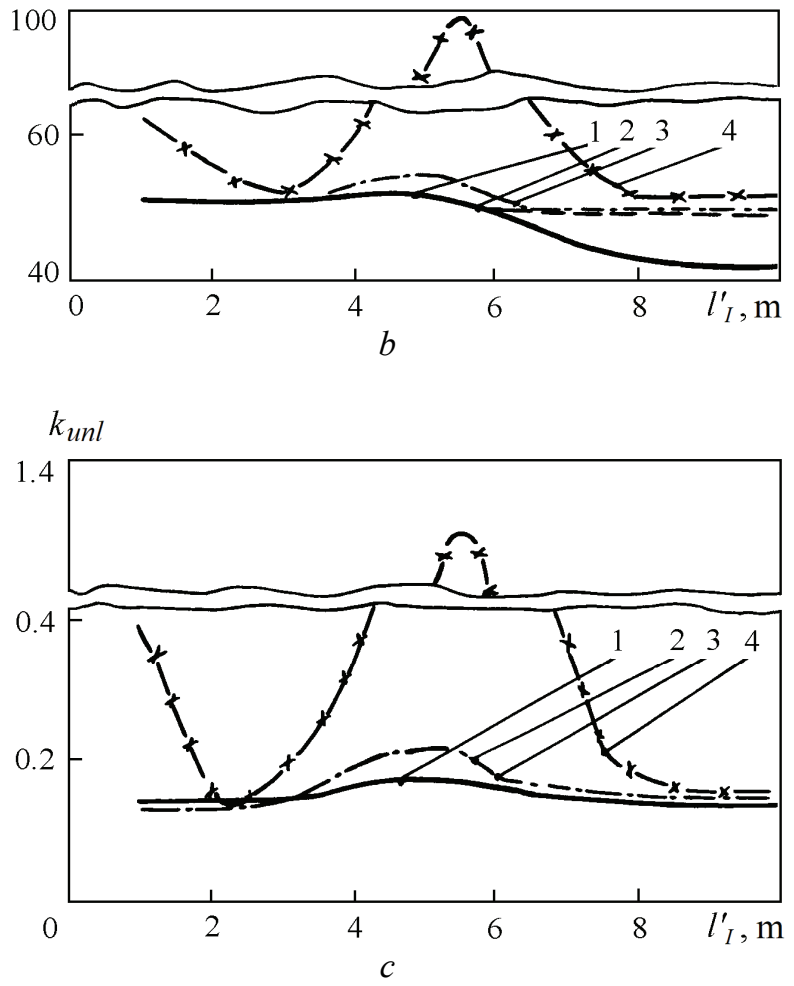

Fig. 4. Dependencies of the maximum values of the vertical and horizontal forces acting on the wheels and rails, as well as the wheel unloading coefficients, on the parameters of the horizontal irregularities of the straight part of the track without vertical irregularities: $a, b$ - vertical and horizontal forces acting on the wheels, respectively; $c$ - wheels unloading coefficient; $1,2,3,4$ - horizontal irregularity depth $0.005 ; 0.015 ; 0.030 ; 0.050 \mathrm{~m}$, respectively.

It should also be noted that the difference between the results obtained for calculation schemes, in which each wheel pair is represented as one unit and as three solid bodies (axle and two wheels) (Fig. 1), reaches 35-66 \% for loading indicators and 35-61\% for wagons movement safety indicators.

It is noted that the phenomenon of resonance is more expressed on vertical forces than on horizontal ones. This results from the fact that at horizontal sinus wave irregularities of the rail path there are periodic centrifugal forces in the transverse direction. Since the center of gravity of the trolley is located at a considerable height from the rail head, the resulting 
large moments of centrifugal forces cause, due to the small gauge of the track, significant dynamic additions of vertical forces $F_{z}, P_{i n j}, Q_{z i n j r}$ and unloading coefficients $k_{u n l}$.

We also note that the phenomenon of resonance appears much stronger with a greater depth of irregularities $A_{I}^{\prime}$ than with a small one. Therefore, the horizontal irregularities of the path of great depth $\left(A_{I}^{\prime}=0.03 \ldots 0.05 \mathrm{~m}\right)$ should be eliminated during the priority repair of the path.

Since the frequency of forced oscillations due to the transverse unevenness of the path is determined from the expression for $v=\mathrm{v} / l_{I}^{\prime}$, then for each speed, the value $l_{I}^{\prime}$, can be set at which resonance takes place. For example, for speeds of 3 and $6 \mathrm{~m} / \mathrm{s}$, the value of the length of horizontal irregularities corresponding to the resonance is approximately $3.3-3.5$ and $6.7 \mathrm{~m}$, respectively.

The calculation results obtained for the cases of movement of the tip wagon with the speed of 3 and $6 \mathrm{~m} / \mathrm{s}$ confirm that for values of horizontal irregularities close to 3.5 and $6.7 \mathrm{~m}$, there is a resonance.

Thus, on the basis of the above study results, it can be concluded that the greatest danger is the transverse irregularities of the path, whose length corresponds to $v_{o p} / v_{l r}$ (where $v_{o p}$ is rolling stock operating speed; $v_{l r}$ is the oscillation frequency of the tip wagon body during lateral motion or rolling motion). For example, for the studied four-axle tip wagons, the range of operational speeds $3 \ldots 6 \mathrm{~m} / \mathrm{s}$ corresponds to the most dangerous values of the length of the irregularities in the range of $l_{I}^{\prime}=3.5 \ldots 6.7 \mathrm{~m}$. Irregularities of this length, the depth of which is $A_{I}^{\prime}>0.03 \mathrm{~m}$, should be eliminated in the priority work on the repair of the rail track.

\section{Conclusions}

1. The expedient choice of the calculation scheme of the mechanical system "four-axle tip wagon - rail track", which takes into account the main design features of both the tip wagon and the rail track, is substantiated. It is shown, in particular, that when choosing a tip wagon calculation scheme, it is necessary to consider the design features caused by the mounting of the wheels on the axles of the wheelsets. The inertial and elastic-dissipative properties of elements of the rail track are expediently taken into account by the representation of rails, sleepers and bases in the form of concentrated masses for each wheel on springs with dampers (one mass on an elastic-dissipative element in the vertical and transverse directions).

2. It is established that in the operational speed range, the movement of the four-axle typical tip wagon is stable.

3. Based on the analysis of the results of studies of the own and forced oscillations of the tip wagon, it was shown that for the four-axle typical tip wagon, with certain combinations of parameters of track irregularities and speeds of movement of the tip wagon, resonance modes occur due to horizontal irregularities of the rail track. Under such driving conditions, the large level of loading of the tip wagon elements and rail track can take place, and therefore movement safety will not be ensured.

4. In order to guarantee the acceptable level of loading indicators for the four-axle tip wagon and elements of the rail track, it is necessary to eliminate the irregularities of a large depth and short vertical irregularities during urgent repairs work.

5. Algorithms and effective mathematical models were developed for the study of spatial oscillations of four-axle mine wagons with free and rigid mounting of the wheels on axles of wheelsets when moving along an inertial, elastic-dissipative rail track with an arbitrary shape in the plan and profile of the track. 
6. New methods are presented and the values of indicators of loading, oscillations and stability of movement of special mine vehicles with the free and rigid mounting of the wheels on axles of wheelsets with a complex rail track structure, which has significant deviations in the track irregularities, are determined.

7. The phenomenon of resonance due to the proximity of the frequencies of forced oscillations and the frequencies of natural oscillations of the carriages, as well as the critical speeds of mine rolling stocks in a safe driving mode, has been established.

8. The developed algorithms and mathematical models of dynamic processes make it possible to effectively carry out a study of the load indicators and the stability of the movement of the created vehicles of mining enterprises for prospective operating conditions, as well as to form the initial requirements for the technical requirements on new-level technical products.

\section{References}

1. Lazaryan, V.A. (1985). Dinamika transportnykh sredstv. Kyiv: Naukova Dumka

2. Lazaryan, V.A., Dlugach, L.A., Korotenko, M.L. (1972). Ustoychivost dvizheniya relsovykh ekipazhey. Kyiv: Naukova dumka

3. Radchenko, N.A. (1988). Krivolineynoe dvizhenie relsovykh transportnykh sredstv. Kyiv: Naukova dumka

4. Garg, V.K., Dukkipati, R.V. (1988). Dinamika podvizhnogo sostava. Perevod s angliyskogo pod redaktsiey N.A. Pankina. Moskva: Transport

5. Verigo, M.F. Kogan, A.Ya. (1986). Vzaimodeystvie puti i podvizhnogo sostava. Moskva: Transport

6. Ushkalov, V.F. (1989). Matematicheskoe modelirovanie kolebaniy relsovykh transportnykh sredstv. Kyiv: Naukova dumka

7. Novikov, E.E., Zemlyanoy, E.F., Hovorukha, V.V. (1983). Dinamika i prochnost shakhtnykh transportnykh sosudov. Kyiv: Naukova dumka

8. Polyakov, N.S., Novikov, E.E. (1973). Dinamika shakhtnogo relsovogo transporta. Kyiv: Naukova dumka

9. Hovorukha, V.V., Novikov, E.E., Goldberg, Yu.I. (1976). Issledovanie gorizontalnykh sil vzaimodeystviya vagonetok s ostryakami shakhtnykh strelochnykh perevodov. Dinamika i prochnost gornykh mashin: Sbornik trudov Instituta geotehnicheskaya mekhanika AN USSR. Kyiv: Naukova dumka, 4

10. Polyakov, N.S., Hovorukha, V.V., Novikov, E.E. (1970). Uluchshenie konstruktsii relsovogo puti. Coal of Ukraine, 2, 33-35 